\title{
Letter from the new Editor-in-Chief
}

\author{
Katsushi Tokunaga
}

Published online: 12 January 2007

(C) The Japan Society of Human Genetics and Springer 2007

It is my great honor to serve as Editor-in-Chief of the Journal of Human Genetics, the official journal of the Japan Society of Human Genetics. The JHG has achieved a high reputation in the past several years under the excellent leadership of my predecessor as Editor-in-Chief, Professor Yusuke Nakamura. The journal has truly become an internationally recognized publication presenting important articles contributed by world-renowned human geneticists with a wide range of specialties. Following the completion of human genome sequencing, we have entered a tremendously productive era for human genetics. For example, enormous numbers of variations/polymorphisms in a variety of sizes, including SNPs and $\mathrm{CNVs}$, have been catalogued, and the search for genes relevant to Mendelian and complex disorders as well as genes subjected to natural selection has been accelerated. Without doubt, the contribution of human genetics to clinical tests and translational research for clinical medicine will be greatly increased. In cooperation with the new associate editors and editorial board members, I will make every effort to continue the successful publication of the $J H G$ in a manner that will satisfy our readers. We look forward to receiving your manuscripts for original and review articles, as well as your suggestions for further improvement of the JHG.

\section{K. Tokunaga}

Editor-in-Chief, Journal of Human Genetics

1 January 2007

K. Tokunaga $(\bowtie)$

Tokyo, Japan

e-mail: tokunaga@m.u-tokyo.ac.jp 